\title{
CRIANÇAS COM DEFICIÊNCIA E A IMPORTÂNCIA DO BRINCAR NO RECREIO
}

Recebido em: $15 / 12 / 2020$

Aprovado em: 05/05/2021

Licença:@) (1) @

Rejane Helena Damas ${ }^{1}$

Escola Municipal Cecília Meireles

Juiz de Fora - MG - Brasil

Neil Franco Pereira de Almeida ${ }^{2}$

Universidade Federal de Juiz de Fora (UFJF)

Juiz de Fora - MG - Brasil

RESUMO: Este estudo apresenta reflexões teóricas sobre um projeto de intervenção pedagógica realizado entre 2018 e 2019 que teve como objetivo analisar se a introdução de brincadeiras e jogos nos momentos de recreio em uma escola da Rede Municipal de Ensino de Juiz de Fora poderia promover a inclusão de crianças com deficiência. Ancorou-se na correlação de fontes bibliográficas, documentais e empíricas utilizandose para a construção de dados de observações das crianças e conversas informais com docentes que foram registradas em um caderno de campo. O processo de se organizarem autonomamente nas brincadeiras do recreio seria uma possível realidade mediante um processo de intervenção mais prolongado, uma vez que o interesse em brincar foi manifestado mesmo sem a mediação das professoras, assim como a iniciativa de integração por parte das crianças daquelas com diagnóstico de Síndrome de Down.

PALAVRAS-CHAVE: Síndrome de Down. Jogos e Brinquedos. Educação Básica.

\section{CHILDREN WITH DISABILITIES AND THE IMPORTANCE OFPLAYING AT RECESS IN SCHOOL}

ABSTRACT: This paper presents theoretical reflections on a pedagogical intervention project carried out between 2018 and 2019, aiming to analyze whether the introduction of games at recess in a public school in the Educational system of Juiz de Fora could promote the inclusion of children with disabilities. The study was based on the correlation of bibliographic, documentary and empirical sources and the construction of data relied on observing children playing and having informal conversations with teachers. Both actions were recorded in a field notebook. The children's process of organizing themselves autonomously in the recreational games would be a possible reality through a more prolonged intervention process, since the kids' interest in playing

\footnotetext{
${ }^{1}$ Especialista em Educação Inclusiva em Contextos Escolares.

${ }^{2}$ Doutor em Educação, professor da Universidade Federal de Juiz de Fora, Coordenador do Grupo de Estudos e Pesquisa Corpo, Culturas e Diferença.
} 
was manifested even without the mediation of the teachers, as well as their initiative of including those ones who had diagnosis of Down syndrome.

KEYWORDS: Down Syndrome. Games and Toys. Basic Education.

\section{Introdução}

A temática sobre inclusão de alunos (as) com deficiências na escola regular não é um tema novo e tem sido bastante discutido na atualidade. Confirma-se tal fato pela criação de leis que concedem e ampliam os diretos relativos à educação dessas pessoas no cenário escolar, dentre elas destacam-se: a Constituição Federal (BRASIL, 1988), a Lei de Diretrizes e Bases da Educação - LDBN (BRASIL, 1996), Estatuto da Criança e do Adolescente - ECA (BRASIL, 1990), Declaração de Salamanca (1994), e a Política Nacional de Educação na Perspectiva da Educação Inclusiva (BRASIL, 2008).

Essas normativas surgem como forma de assegurar a educação do público da Educação Especial, ou seja, pessoas com deficiência, Transtornos Globais de Desenvolvimento e com Altas Habilidades/Superdotação. Assim, essas políticas públicas foram e estão sendo implementadas objetivando garantir o direito do público da Educação Especial de aprender na escola regular, estando próximos a outros(as) alunos(as)sem nenhuma discriminação (BRASIL, 2008).

Neste contexto, Santana (2016) aponta que o século XX trouxe muitas dúvidas e incertezas acerca da Educação Especial e, assim, a partir de novas reflexões por parte da sociedade, a inclusão de pessoas deficientes na escola regular começou a ganhar novos olhares.

As leis acima citadas surgiram para garantir a esse público o direito de estar com seus pares e o direito a aprendizagem. No contexto de Juiz de Fora, incluir o (a) aluno (a) com deficiência na escola regular surgiu como uma forma de valorizar esse ser humano, que ao longo do tempo ficou relegado as escolas especializadas em deficiência 
como, por exemplo, a Associação de Pais e Amigos dos Excepcionais (APAE) e a Escola Estadual Maria das Dores; ambas localizadas em Juiz Fora, sendo a segunda referência nessa área.

O tema proposto para este estudo advém da trajetória acadêmica como professora formada em Magistério e licenciada em História pela Universidade Federal de Juiz de Fora (UFJF). Iniciei meu trabalho como docente em séries inicias do ensino fundamental há cerca de quinze anos na Rede Municipal de Ensino convivendo diariamente com crianças com alguma manifestação de necessidade especial. No ano de 2018 e 2019, atuando ainda como professora do terceiro ano numa escola da Rede Municipal de Juiz de Fora, detive-me a observar mais atentamente o envolvimento e as brincadeiras dessas crianças durante os momentos do recreio. Neste período cursava uma Pós-graduação latu sensu oferecida pela Faculdade de Educação da UFJF, intitulada "Especialização em educação inclusiva em contextos escolares", instigandome ainda mais entender os processos interacionais entre crianças diagnosticadas como deficientes e crianças não deficientes.

Na escola, o recreio acontece todos os dias da semana, com duração de quinze minutos, onde brincavam juntas três turmas de alunos (as) totalizando setenta e cinco crianças com idades entre oito e nove anos, sendo que, deste total, dois meninos e uma menina, foram diagnosticados (as) com Síndrome de Down (SD).

De acordo com Dessen e Silva (2002) a SD, ou Trissomia do cromossomo 21, é uma alteração genética causada por um erro na divisão celular durante a divisão embrionária que leva a pessoa a possuir três cromossomos no par 21, quando, na verdade, deveria possuir dois. Essa alteração genética provoca no sujeito atrasos no desenvolvimento global e nas funções motoras do corpo como a hipotonia muscular (diminuição do tônus muscular dos membros e do tronco), sonolência acentuada, 
distúrbios da fala, dente outros. Dessen e Silva (2002) apontam ainda que uma característica marcante na SD seja a deficiência intelectual que pode se apresentar em graus variados em cada pessoa, ainda que seja um discussão ainda em construção nos meios acadêmicos dessa área.

Ao observar as brincadeiras e a interação desses (as) alunos (as) durante os momentos do recreio, percebi que os (as) três alunos (as)com SD eram reunidos num pequeno grupo isolado dos demais, acompanhados (as) por suas respectivas Professoras Bidocentes - assim como são denominadas nas escolas da Rede Municipal de Ensino de Juiz de Fora -, pois dividem a docência da sala de aula com a Professora Regente. A Professora Bidocente acompanha o (a) discente com alguma deficiência nas suas necessidades mais específicas como ir ao banheiro, alimentação, organização do material escolar, copiar os conteúdos no caderno e uma série de outras coisas.

Durante esses momentos do recreio, observei que as crianças com SD ficavam separadas das demais sem acontecer interação entre elas e as demais. Muitas vezes, ficavam paradas olhando umas para as outras, não havendo nenhuma intervenção de ambas as professoras para que o grupo fizesse qualquer atividade que propiciasse a socialização.

Sendo assim, surgiu a questão/problema deste estudo: A realização de uma proposta de intervenção pedagógica com a introdução de brincadeiras e/ou jogos no recreio em uma Escola da Rede Municipal de Ensino na cidade de Juiz de Fora promoveria a interação de discentes com deficiência com as demais crianças da escola?

Freitas (2010) enfatiza que as crianças aprendem brincando e a interação entre elas é fundamental para seu desenvolvimento e ainda ressalta que a escola desempenha um papel de grande importância no quesito interação, pois ela é democrática e agrega variados tipos de discentes. A Declaração Universal dos Direitos da Criança (1959) 
destaca que jogos e brincadeiras devem ser desfrutados plenamente pelas crianças (BRASIL, s/d). Neste sentido, “[...] é através dos brinquedos e brincadeiras que as crianças desenvolvem suas habilidades, percepções, raciocínio, criatividade e aprendem sua relação com si mesmas e com os outros.” (BRASIL, s/d, p. 9). Para o filósofo Henri Wallon "[...] a comunicação entre as crianças acontece quando elas brincam e dessa forma elas aprendem a se expressar e assim desenvolve-se culturalmente." (BRASIL, s/d, p. 11). E ainda, no caso das crianças com deficiência, o brincar poderá ser utilizado para que elas superem suas dificuldades.

Diante do exposto acima, percebe-se que os jogos $\mathrm{e}$ as brincadeiras desempenham um papel importante na vida e no desenvolvimento de todas as crianças, portanto, justificando a relevância deste estudo cujo objetivo foi realizar uma proposta de intervenção pedagógica com a introdução de brincadeiras e/ou jogos no recreio em uma escola municipal de Juiz de Fora, com o intuito de promover a interação do corpo discente, e, em especial, aqueles (as) com SD.

\section{Metodologia}

Este Projeto de Intervenção Pedagógica fundamenta-se numa abordagem qualitativa, ancorado na correlação de fontes bibliográficas, documentais e empíricas. Para a construção dos dados empíricos foram utilizadas observações junto às crianças e docentes e de conversas informais com as docentes (Regentes e Bidocentes), dados estes registrados no caderno de campo da investigadora. Tal proposta metodológica se justifica, segundo Goldenberg (2004, p. 47), pelo fato de:

[...] o pesquisador coleta os dados através da sua participação na vida cotidiana do grupo ou da organização que estuda, observa as pessoas para ver como se comportam, conversa para descobrir as interpretações que têm sobre as situações que observou, podendo comparar e interpretar as respostas dadas em diferentes situações. 
Nessa perspectiva, Lüdke e André (1986) ressaltam que a pesquisa qualitativa preocupa-se com a maneira com que os fenômenos ocorrem dentro de um determinado grupo e quais significados são atribuídos aos fenômenos sociais por esses sujeitos.

O desenvolvimento da Intervenção Pedagógica aconteceu entre o segundo semestre de 2018 e primeiro semestre de 2019 em uma escola Municipal na cidade de Juiz de Fora - MG.

As observações aconteceram no turno da tarde em três turmas do terceiro ano do ensino fundamental, compostas cada uma por duas professoras sendo uma Regente de turma e a outra Bidocente, somando no total seis professoras que supervisionam setenta e cinco crianças.

Como forma de preservar as identidades das professoras, elas foram identificadas de B1, B2, B3 para as Bidocentes e R1, R2, R3 para as Regentes de sala. A mesma regra se aplicou aos nomes das crianças com SD mencionadas no estudo para as quais atribuiu-se nomes fictícios. Este procedimento respeita a determinação da Resolução CNS/196 que normatiza a pesquisa com seres humanos.

Neste sentido, a metodologia do estudo se estruturou em seis fases:

1. Realizar um levantamento teórico sobre as questões que envolviam a pesquisa através da busca de referenciais teóricos sobre a relação deficiência e contexto escolar; identificação de normativas que regem o processo de inserção de pessoas com deficiência na escola e, por fim, referenciais que permitiriam entender as relações entre o brincar no contexto escolar.

2. Investigar como se processava a interação dos (as) alunos (as) com deficiência com os (as) demais alunos (as) nos momentos de recreio na escola investigada. 
3. Identificar através de conversas informais com as professoras regentes e/ou bidocentes, como e se ocorria interações entre alunos (as) com deficiência e os (as) demais estudantes.

4. Verificar se nas intervenções ocorridas no recreio entre o corpo discente aconteciam interações por experiências do brincar, em especial, envolvendo crianças com deficiência, motivadas ou não pelo corpo docente.

5. Propor atividades lúdicas no recreio que buscassem a interação entre o corpo discente e, em especial, envolvendo discentes com deficiência.

6. Verificar se essas atividades lúdicas propostas poderiam gerar atitudes posteriores de autonomia dos (as) discentes para ser organizarem e brincarem no recreio de forma coletiva, envolvendo as crianças com deficiência; aspecto este que seria verificado pela via de observação desse espaço após a intervenção.

Num passado não muito distante, crianças com alguma deficiência eram consideradas como seres com patologia e/ou incapazes para a vida em sociedade e estudar numa escola regular era um sonho distante (GAIA, 2017). Deimling e Moscardine (2012) ressaltam que a sociedade brasileira importava muito pouco com a pessoa com deficiência e que a inclusão dessas pessoas na escola regular seria um dos grandes desafios da contemporaneidade.

Ainda segundo Gaia (2017), o direito a educação para a pessoa com deficiência é algo bastante recente. No Brasil, o cenário começa a ganhar vulto com a nova Constituição Federal (BRASIL, 1988) que garante em seu artigo $5^{\circ}$ que todas as pessoas são iguais, sem distinção de qualquer natureza. A Lei de Diretrizes e Bases da Educação - LDBN - (BRASIL, 1996), no seu artigo $2^{\circ}$, reafirma o direito de todo (a) cidadão de ir à escola, sendo, "a educação, dever da família e do Estado"; e no artigo $3^{\circ}$ : esse dever 
deve também resguardar a "igualdade de condições para o acesso e permanência na escola".

A partir do direito de frequentar uma escola garantido por lei, os (as) alunos (as) com deficiências começaram a chegar às escolas regulares que se deparou com o grande desafio da inclusão, pois a escola se viu diante do despreparo do corpo docente e administrativo, barreiras arquitetônicas, elaboração de um novo currículo e uma série de outros entraves desfavoráveis a inclusão, assim, a escola vem se "adaptando" ao novo. Essa série de fatores impedem as escolas na atualidade de propiciar ao (à) aluno (a) com deficiência momentos de aprendizagem e interação com seus pares e, principalmente, durante o recreio.

Nessa perspectiva, Cordazzo e Vieira (2007) e Freitas (2010) interpretam que o brincar é capaz de promover o desenvolvimento da fala, do físico, da aprendizagem, da criatividade, como também desenvolvem a interação social. Assim, a introdução da brincadeira nos momentos de recreio seria uma forma de aproximar as crianças umas das outras, promovendo novas aprendizagens e possibilitar novas reflexões por parte do corpo docente sobre o tema.

Dessa forma, justificando a relevância deste estudo pautado nas argumentações acima, entende-se esta proposta como um tema atual e de muita importância pelo seu potencial de despertar novos olhares sobre as capacidades de interação e aprendizagem dos (as) alunos (as) com deficiência, em particular, pessoas com SD.

\section{Descrição da Escola}

A escola na qual se desenvolveu a Intervenção Pedagógica pertence à Rede Municipal de Ensino de Juiz de Fora - MG, localizada na Zona Norte e foi construída há aproximadamente quarenta anos. No período de realização do projeto de intervenção 
a instituição funcionava em dois turnos (manhã e tarde) e, no período da construção dos dados para o estudo, atendia aproximadamente mil discentes matriculados(as) desde a educação infantil até o nono ano do ensino fundamental. Atuavam cerca de cem docentes em dois turnos (manhã e tarde) e quatro coordenadoras pedagógicas que também trabalhavam nos dois turnos.

Estruturalmente, a escola possuía vinte salas de aula - sendo uma delas destinada ao Atendimento Educacional Especializado (AEE), Laboratório de Ciências e Informática, Biblioteca, Secretaria, Sala dos (as) Professores (as), Sala da Direção e Coordenação, Secretaria, uma Brinquedoteca e dois banheiros masculinos e femininos. Não possuía quadra para a prática de esportes ou para realização de Educação Física, assim, era utilizado um espaço externo em que aconteciam os recreios e as aulas de Educação Física. Este espaço era pequeno em relação ao número de alunos(as) matriculados(as) na escola, com isso, os momentos de atividades fora da sala de aula eram realizados por agrupamentos de séries, ou seja, a cada quinze minutos brincavam aproximadamente setenta e cinco discentes (três turmas de 25 alunos cada).

A escola, visando atender aos (às) alunos (as)com deficiência providenciou algumas modificações na sua arquitetura como a instalação de rampas, ampliação das portas dos banheiros e colocação de corrimões. A escola tentava se adequar para atender da melhor forma possível os quesitos necessários para acessibilidade de pessoas com necessidades especiais, uma vez que a construção é muito antiga. Há um longo caminho a percorrer, com isso, a escola ainda não era uma escola totalmente acessível.

\section{As Docentes e Crianças com Deficiência Envolvidas na Proposta de Intervenção}

O total de turmas observadas na escola somava juntas setenta e cinco alunos (as) das quais três crianças foram diagnosticadas com $\mathrm{SD}$, sendo dois meninos e uma 
menina. Uma das crianças com SD, identificada aqui como Paulinho, estava com oito anos de idade e estudava na escola desde a educação infantil. Além da professora regente de sala, atua junto a ela uma professora que a auxiliava nas tarefas do dia-a-dia, pois associada à $\mathrm{SD}$, Paulinho possuía miopia muito elevada usando óculos para correção visual. Apresentava também dificuldades na locomoção e equilíbrio ao andar.

A segunda criança, identificada como Dilsinho, encontrava-se também com oito anos e estudava na escola desde o primeiro ano do ensino fundamental. Assim como Paulinho, possuía uma professora bidocente pelo motivo de não controlar os esfíncteres e não poder ingerir certos alimentos.

A terceira criança era uma menina, Júlia. Encontrava-se com oito anos de idade e estudava na escola desde o segundo ano do ensino fundamental. Além da professora regente, era também atendida por uma professora bidocente por não controlar os esfíncteres.

Neste sentido, essas professoras bidocentes assumiam a função de auxiliar os (as) discentes que apresentavam ausência de autonomia para realização de ações cotidianas como higiene, locomoção, alimentação e atividades escolares em conformidade com a lei Federal 13.146/2015 art. $3^{\circ}$ Inciso XIII em que são definidas como: “[...] profissional de apoio escolar: pessoa que exerce atividades de alimentação, higiene e locomoção do estudante com deficiência e atua em todas as atividades escolares nas quais se fizer necessária e modalidades de ensino...].” (BRASIL, 2015).

Todas as seis professoras (três regentes e três bidocentes) possuíam nível superior em Pedagogia e apenas uma delas realizou cursos voltados para a área da Educação Especial. As demais relataram que a falta de tempo inviabilizou a realização de cursos. Manifestaram ainda que atuavam no magistério há vários anos e sempre trabalharam com crianças com alguma deficiência. 


\section{$1^{a}$ Etapa da Intervenção Pedagógica: Observação Inicial do Recreio}

No Projeto Político Pedagógico (PPP) da escola onde aconteceu a intervenção, no capitulo que versa sobre a inclusão, enfatiza-se a importância do acolhimento dos (as) alunos (as) com deficiência no âmbito da escola e destaca o compromisso do corpo docente para com essas pessoas. Na escola, os (as) docentes tomavam conta do recreio e, observando os momentos de interação das crianças nesse espaço, percebeu-se que os (as) alunos (as) com deficiência ficavam a parte nas brincadeiras. Durante a observação desses momentos que aconteceram de forma mais efetiva entre os meses de novembro e dezembro de 2018, três crianças diagnosticadas com SD se destacaram, sendo dois meninos e uma menina, com oito anos de idade, muito amáveis e interessados (as) em aprender. Porém, manifestavam pouca autonomia para realizarem conversas e brincadeiras por iniciativa própria, sendo assim, necessitavam que alguém iniciasse e estimulasse as brincadeiras e as conversas. Na ausência desse incentivo, ficavam e/ou brincavam sozinhos (as) ou somente interagiam com as professoras bidocentes.

Possivelmente, este fato acabava comprometendo seu desenvolvimento global, um vez, que o brincar, para uma criança com ou sem deficiência, desencadeia a interação e um exercício de imaginação capaz de promover a busca de novas habilidades enriquecedoras do processo de aprendizagem. Brandt; Santos e Vivente (2015) confirmam essa afirmativa ao destacarem que a partir da brincadeira a criança pode aprender muito sobre coisas primordiais para sua vida cotidiana como: tomar banho alimentar-se, fazer a sua higiene e que o professor pode ser um dos mediadores dessas ações.

A partir de tal constatação, procurou-se estabelecer conversas com as professoras dessas crianças indagando o porquê de não serem inseridas nas brincadeiras e conversas nesses momentos. A professora B1 respondeu que seu aluno, Paulinho, não 
podia brincar no recreio no pátio da escola porque sua mãe tinha muito medo dele cair e se ferir devido à alta miopia. Assim, para evitar acidentes com queda, ela não permitia que ele brincasse no meio das demais. A professora R1, que trabalhava em conjunto com a B1, disse concordar com a opinião da mesma, pois assim elas evitavam problemas com a família da criança.

A professora B2, que acompanhava o aluno Dilsinho, explicou que ele não gostava de muita gente por perto e que, muitas vezes, "preferia ficar sozinho com seus pensamentos". Confirmando essa percepção, a docente R2 disse que o discente não interagia com os demais por ser muito tímido e por não gostar de muita conversa.

A professora B3, que acompanhava a aluna Júlia, disse que ela era uma aluna muito "levada" e poderia agredir outras crianças fisicamente, uma vez que cuspia nos(as) colegas quando contrariada em seus desejos. Diante disso, os(as) demais alunos(as) a evitavam. Não diferente dessa explicação, a professoraR3 argumentou que Júlia não era inserida nas brincadeiras pelos(as) demais colegas porque era muito temperamental e a todo o momento criava conflitos como cuspir e beliscar.

Após as conversas com as professoras, realizou-se uma busca por autores(as) que tratassem sobre o assunto "brincar das crianças com SD". Descobriu-se que a SD não impede as crianças de brincar e interagir, muito pelo contrário, a interação com seus pares pode propiciar o desenvolvimento cognitivo, linguagem e habilidades motoras (GABRILLI, 2018; FREITAS, 2010; SABINO, 2011, UNICEF, 2012; BRANDT; SANTOS; VIVENTE, 2015).

A partir das conversas com as professoras regentes e bidocentes e da pesquisa bibliográfica, sugeriu-se a elas selecionar e introduzir nos momentos de recreio brincadeiras que não oferecessem riscos de acidentes e, assim, poderiam promover a interação dos(as) alunos(as) com SD com os (as) demais nos momentos de recreio. 
Pautado nesses princípios e da compreensão inicial do universo a ser investigado, partiu-se para o planejamento e realização da intervenção junto aos(às) discentes no recreio.

\section{$2^{a}$ Etapa de Intervenção Pedagógica: o Recreio como Espaço de Inclusão}

A proposta de intervenção definiu-se como a introdução de brincadeiras e jogos nos momentos de recreio dos (as) alunos (as) do terceiro ano na Escola Municipal onde a pesquisadora trabalhava como professora regente, convidando também para esses momentos os (as) alunos (as) diagnosticados (as) com SD. Esses momentos aconteceram durante cinco dias na semana em que as professoras regentes e bidocentes estariam na escola, durante quinze minutos diários junto a seus/suas discentes no recreio. A proposta de intervenção aconteceu em duas fases:

\section{$1^{\text {a }}$ Fase: Aplicação do Projeto pela Pesquisadora}

No período de duas semanas, entre os dias 01 e 11 do mês de abril de 2019, no pátio da escola, a professora responsável pela intervenção se manifestou convidando e mediando as brincadeiras entre as crianças. Utilizou-se de objetos como peteca, bola, corda, anel, etc.

As brincadeiras sugeridas foram:

1. Peteca - quatro crianças se posicionam em forma de roda voltadas para o centro do círculo, a peteca é arremessada entre as crianças que a deve manter no ar.

2. Pula corda - duas crianças batem a corda e outra pula com variações a gosto.

3. Corre-cutia - sentadas em círculo e voltadas para o centro da roda, uma criança corre em volta da roda ao som de uma cantiga e deixa um objeto atrás de um (a) colega a sua escolha. O (a) colega pega o objeto, se levanta, e corre atrás de 
quem deixou. Esta última correrá ao redor da roda com o objetivo de se sentar no lugar da criança antes que seja tocada por ela.

4. Passar o anel - as crianças se sentam em forma de roda e colocam as mãos uma encostada a outra. A criança com o anel vai passando a suas mãos unidas - com o anel entre elas, dentro das mãos dos (as) colegas. A pessoa que passou o anel escolhe uma criança do grupo que tentará descobrir com quem ficou o anel.

5. Arremesso de bola no cesto - as crianças são posicionadas em fila e uma de cada vez tenta arremessar a bola no cesto.

6. Morto-Vivo - Em grupos, a professora anuncia as palavras "morto" e "vivo" que são representadas pelas crianças se posicionando, respectivamente, próximo ao chão ou na posição de pé.

O planejamento das atividades se deu entre os meses de fevereiro e março de 2019, logo em seguida ao retorno do ano letivo, em que observações esporádicas foram realizadas com o intuito de confirmar as impressões evidenciadas no final de $2018 \mathrm{em}$ que percebia pouca interação ente crianças com deficiência e demais colegas nas brincadeiras desenvolvidas no recreio.

Como descrito acima, as brincadeiras e jogos foram escolhidos observando aquelas que evitassem correr; pois eram muitos (as) alunos (as) e pouco espaço físico, além da tentativa de atender às orientações dadas pelas professoras regentes e bidocentes em relação aos (às) discentes com SD. Foi proposto às seis professoras o desafio de na primeira fase da intervenção convidar e incentivar os (as) alunos (as) para brincarem juntos incluindo os três alunos(as) com SD, durante os quinze minutos do recreio, introduzindo as brincadeiras referidas acima.

Nas duas primeiras semanas da aplicação da intervenção com a mediação das docentes, cada professora regente juntamente com a professora bidocente ficaram a 
frente de um grupo de 25 alunos (as) oferecendo duas brincadeiras que aconteciam a cada três dias (vide Quadro 01, abaixo). As crianças se agruparam conforme as brincadeiras que desejavam participar, se alternando ora em uma ora em outra.

Quadro1: Brincadeiras com Intervenção/ Dias de Aplicação

\begin{tabular}{c|c|c|c|c|c}
\hline Peteca & Corre Cutia & $\begin{array}{c}\text { Arremesso de } \\
\text { bola na cesta }\end{array}$ & Passar o anel & Morto-Vivo & Pular corda \\
\hline $01 / 04$ & $01 / 04$ & $04 / 04$ & $04 / 04$ & $09 / 04$ & $09 / 04$ \\
$02 / 04$ & $02 / 04$ & $05 / 04$ & $05 / 04$ & $10 / 04$ & $10 / 04$ \\
$03 / 04$ & $03 / 04$ & $08 / 04$ & $08 / 04$ & $11 / 04$ & $11 / 04$ \\
\hline
\end{tabular}

Fonte: elaborado pelos autores

Durante a primeira fase onde as professoras convidavam e incentivavam os (as) alunos (as) para as brincadeiras, observou-se que, no geral, eles (as) gostaram muito das novas modalidades introduzidas no recreio, sempre querendo saber qual seria a brincadeira do dia. Já as crianças com SD necessitavam serem estimuladas e orientadas quanto a esses momentos.

Dilsinho, por exemplo, no primeiro dia, aceitou brincar após o convite das professoras e dos (as)colegas, mas sempre ao lado da professora bidocente, se recusando a ir para perto dos demais alunos (as). A brincadeira que mais demonstrou interesse foi morto-vivo onde todos (as) os (as) discentes reunidos (as) num grande grupo participaram juntos (as). Nas brincadeiras que demandavam maior interação como jogo de Peteca, Corre-Cutia, Passar o anel e Pular-corda, dizia estar cansado e que não queria brincar. Disse ainda estar com ciúmes da sua professora com as outras crianças a segurava pela mão e dizia querer brincar somente com ela. Nos demais dias da semana demonstrou muito pouco interesse pelas brincadeiras, alegando sempre estar cansado.

Ao contrário de Dilsinho, o aluno Paulinho, apesar da sua miopia acentuada, manifestou muita satisfação por estar com os (as) demais colegas. Quando realizado o convite para que participasse das brincadeiras, aceitou prontamente, participando de todas. Quando os (as) colegas o chamavam para brincar, ele os abraçava e dizia “amigos" e se enturmava com os (as) demais. Já na primeira semana de intervenção 
pôde-se perceber certa autonomia por parte de Paulinho, pois ele não mais esperava pelo convite e se dirigia para o local das brincadeiras.

Assim como Paulinho, a aluna Júlia demonstrou muito interesse em participar das brincadeiras com os (as) demais colegas; quando convidada se mostrava muito receptiva. No decorrer dos dias, durante as brincadeiras se envolveu em vários conflitos. Percebeu-se que ela necessitava interagir e aprender a colaborar mais em brincadeiras coletivas, tendo no começo um (a) adulto (a) mediando essas interações, pois ainda se mostrava imatura e, às vezes, egoísta, demonstrando certa dificuldade para assimilar as regras e respeitar os (as) colegas. Nas brincadeiras que requeriam regras, ela se recusava a segui-las, criava as suas próprias regras, como, por exemplo, no jogo, quando de posse da peteca, se recusava a jogá-la para outra criança. Na hora de pular a corda, queria pular o tempo todo (embora ainda não dominasse perfeitamente a técnica), assim, a presença da mediadora/professora quase sempre era requisitada pelas demais crianças.

\section{$2^{\text {a }}$ Fase: Observação de Possíveis Efeitos das Intervenções}

No período de duas semanas após a intervenção, entre os dias 15 e 29 do mês de abril de 2019, no pátio da escola, a professora responsável pela intervenção observou as crianças após a intervenção com o intuito de identificar se os (as) discentes se organizariam e realizariam as brincadeiras sem a mediação da investigadora. Os materiais para realização das brincadeiras foram disponibilizados e a professora somente sugeria a brincadeira do dia de acordo com o planejamento descrito no Quadro 02, semelhante ao das semanas anteriores.

Quadro2: Brincadeiras sem Intervenção/ Dias de Aplicação

\begin{tabular}{c|c|c|c|c|c}
\hline Peteca & Corre Cutia & $\begin{array}{c}\text { Arremesso de } \\
\text { bola na cesta }\end{array}$ & Passar o anel & Morto-Vivo & Pular corda \\
\hline $15 / 04$ & $15 / 04$ & $22 / 04$ & $22 / 04$ & $25 / 04$ & $25 / 04$ \\
$16 / 04$ & $16 / 04$ & $23 / 04$ & $23 / 04$ & $26 / 04$ & $26 / 04$ \\
$17 / 04$ & $17 / 04$ & $24 / 04$ & $24 / 04$ & $29 / 04$ & $29 / 04$ \\
\hline
\end{tabular}

Fonte: elaborado pelos autores 
Na segunda etapa da intervenção Dilsinho repetiu o comportamento anterior, manifestou pouco desejo pelas brincadeiras e ficou ao lado da sua professora o tempo todo, como sempre fazia no dia-a-dia.

Por outro lado, nos dias em que não houve a mediação das professoras, Paulinho se soltou ainda mais, porém, sem muita noção das regras das brincadeiras, se recusando a entrar em filas e esperar a sua vez. Na brincadeira de passar o anel, não conseguiu entender como ela funcionava dizendo que o anel era dele; demonstrou muita vontade em aprender a pular a corda, contudo, no contexto mais amplo, evidenciou-se que ele ainda necessitava ser orientado para cada brincadeira. Segundo a sua professora bidocente, nos dias em que sucederam a intervenção durante a aula ele perguntou várias vezes se já era hora do recreio para ir brincar lá fora com os (as) amigos (as).

Na segunda fase da intervenção sem o convite das professoras Julia sempre se mostrou entusiasmada com as brincadeiras e os colegas perguntando a professora que a auxilia durante a aula que queria "brincar de jogar bola", no segundo dia sem o convite das professoras trouxe de casa um anel para "passar nas mãos" das colegas. A mãe de Julia nos relatou que num dos dias ela chegou em casa após a aula e ficou pedindo para levar o anel para a escola pois queria brincar.

Observou-se ainda que Julia demonstrou certa autonomia. No pátio onde aconteceram as brincadeiras soltava-se das mãos da professora e corria para se juntar aos (às) demais colegas, porém, constatou-se que ela continuou a apresentar dificuldades para entender as regras das brincadeiras, mesmo após a intervenção das professoras. Ela ainda empurrava outras crianças entrando na frente dos (as) colegas aparentando impaciência para aguardar a sua vez na fila, o que, por vezes, ocasionava entre atitudes que desencadeavam brigas e empurrões por parte dos (as) demais participantes. Nesses momentos, foi necessária a intervenção das professoras e ao 
terminar o horário do recreio Julia se recusava a entregar os brinquedos e voltar para a sala de aula.

\section{Discussões e Considerações}

Durante as intervenções percebeu-se uma questão bastante significativa. No decorrer de todo o processo da intervenção, identificou-se que as crianças da escola nutrem muito carinho pelo (as) colega com SD e se enchem de cuidados, procurando ajudá-los (as) sempre que necessário. Se manifestaram muito solidários (as). Acredita-se que a questão do cuidar é transmitida pelas professoras às turmas, pois várias vezes, presenciou-se falas dessas docentes do tipo: "Maria, leve a Júlia para beber água", "José, dê a mão ao Paulinho para que ele suba as escadas."

Verificou-se no decorrer das intervenções que é possível promover a interação das crianças com SD nos momentos de recreio e que as outras crianças, no geral, são livres de preconceitos em relação às suas limitações. Para elas, todas são crianças, independente de serem deficientes ou não. Compreendeu-se também que para o desenvolvimento da autonomia no sentido de se organizarem para as brincadeiras no coletivo necessita de mediações diretivas por parte do corpo docente durante certo período de tempo para que as regras sejam assimiladas e consolidadas.

Essas proposições são confirmadas pelos Manuais de brincadeiras inclusivas como o elaborado por Gabrilli, 2018 e o Guia do brincar Inclusivo elaborado pela Unicef (2012) que, em consonância com Freitas (2010) e Brandt; Santos e Vivente (2015),ressaltam que as brincadeiras são capazes de promover aprendizagens significativas para o desenvolvimento infantil.

O processo de se organizarem autonomamente nas brincadeiras do recreio seria uma possível realidade mediante um processo de intervenção mais prolongado, uma vez 
que o interesse em brincar foi manifestado sem a mediação das professoras, em especial, por Paulinho e Julia.

Durante as conversas e observações, notou-se que algumas das professoras das crianças com SD, seguindo orientações dos pais e mães com receio de o (a) filho (a) se machucar, não estimulavam as brincadeiras e a interação por medo da criança se ferir e a família reclamar. Assim, seguiam com o processo de superproteção criando impedimentos que podem interferir no desenvolvimento das crianças com SD. Como bem colocado por Cunha; Blascovi-Assis e Framenghi (2010, p. 446), “[...] atitudes de superproteção, piedade ou rejeição, presentes no núcleo familiar, podem interferir no desenvolvimento dos filhos, incluindo os aspectos sociais e emocionais."

Confirmando essas impressões após o processo de intervenção no recreio com brincadeiras na tentativa de proporcionar maior interação entre crianças de uma escola, em especial, envolvendo aquelas com SD, autores (as) como Nonaka e Pottker (2015) apontam que a criança com SD demoram um pouco mais para adquirir certos conceitos, o que não significa que não consigam incorporá-los. Necessitam de maiores investimentos pedagógicos.

Neste contexto, acredita-se que as crianças com SD, assim como qualquer outra criança, gosta de brincar e de se socializar, basta que sejam convidados (as) e estimulados (as) a participarem das interações e brincadeiras nos momentos de recreio; e brincando em meio aos(às) demais colegas serão incluídos (as) no universo escolar. No entender de Krause; Vichessi e Silva (2018, p. 7), “[...] brincar é essencial na vida das crianças, em seu desenvolvimento e aprendizagem. Por isso, deve ser diário em uma concepção inclusiva de escola." 


\section{REFERÊNCIAS}

BRANDT, Marcia Jane Capuano; SANTOS, Edilson Rebelo dos; VIVENTE, Gislaine Lopes. O brincar na Educação Especial nos primeiros anos das séries iniciais de uma Escola municipal da cidade de Dourados-MS, Revista Interletras, Dourados, v. 3, n. 21.p.1-13, abr./set.2015. Disponível em: https://www.unigran.br/interletras/ed_anteriores/n21/conteudo/artigos/5.pdf. Acesso em: 14 abr. 2019.

BRASIL. Ministério da Educação. Politica Nacional de Educação Especial na Perspectiva da educação Inclusiva. Brasília, 2008. Disponível em: https://centraldefavoritos.com.br/2017/09/06/politica-nacional-de-educacao-especial-naperspectiva-da-educacao-inclusiva/. Acesso em: 14 mai.2019.

Lei Federal n.8069, 13 de julho de 1990. Dispõe sobre o Estatuto da Criança e do Adolescente e dá outras providências. Brasília. 1990. Disponível em: https://criancaeconsumo.org.br/normas-em-vigor/lei-no-8-06990-estatuto-da-crianca-edo-adolescente-eca/. Acesso em: 14 abr.2019.

$\overline{[\mathrm{s} / \mathrm{d}] .}$ p.6-11. Disponível em: http://institutomaragabrilli.org.br/images/stories/pdf/brinquedos.pdf. Acesso em: 07 abr. 2019.

Lei $\mathrm{n}^{\circ}$ 13.146, de 6 de julho de 2015. Institui a Lei Brasileira de Inclusão da pessoa com deficiência. Diário Oficial da União, Brasília, DF, 06 jul. 2015. Disponível em: http://www.planalto.gov.br/ccivil_03/_ato20152018/2015/lei/113146.htm. Acesso em: 15 maio 2019.

Constituição Federal de 1988. Constituição da República Federativa do Brasil de 1988. Brasília, DF: Senado Federal, 1988. Disponível em: http://www2.camara.leg.br/legin/fed/consti/1988/constituicao-1988-5-outubro-1988322142-publicacaooriginal-1-pl.html. Acesso em: 14 jan. 2019.

Ministério da Educação. Lei de Diretrizes e Bases da Educação Nacional. LDBEN 9.394, de 20 de dezembro de 1996. Disponível em: http://www.planalto.gov.br/ccivil_03/leis/19394.htm. Acesso em: 20 dez. 2019.

CORDAZZO Scheila Tatiana Duarte; VIEIRA, Mauro Luis. A brincadeira e suas implicações nos processos de aprendizagem e de desenvolvimento. Estudos e Pesquisas em Psicologia, UERJ, Rio de Janeiro, n.1, Ano 7, $1^{\circ}$ Sem. 2007. Disponível em: file:///C:/Users/Helena/Documents/EXO4.pdf. Acesso em: 14 jan. 2019.

CUNHA, Aldine Maria Fernandes Vohlk; BLASCOVI-ASSIS, Silvana Maria; FIAMENGHI JR, Geraldo Antonio. Impacto da notícia da Síndrome de Down para os pais: histórias de vida. Ciência \& Saúde Coletiva, São Paulo, v.15, n.2, p. 444451.2010 .

DEClARAÇÃo DE SAlamanCA: Sobre Princípios, Políticas e Práticas na Área das Necessidades Educativas Especiais, 1994, Salamanca-Espanha. Disponível em: https://unesdoc.unesco.org/ark:/48223/pf0000139394. Acesso em: 15 jan. 2019. 
DECLARAÇÃO UNIVERSAL DOS DIREITOS DAS CRIANÇAS UNICEF. 20/11/1959. Principio VII. Disponível em: https://www.unicef.org/brazil/os-direitosdas-criancas-e-dos-adolescentes. Acesso em: 07 abr. 2019.

DEIMLING, Natália Neves Macedo; MOSCARDIN, Saulo Fantato. Inclusão Escolar: Política, Marcos Históricos, Avanços e Desafios. Revista online de Política e Gestão Educacional, Araraquara, n.12, p.1-19, jan./jun. 2012. Disponível em: https://periodicos.fclar.unesp.br/rpge/article/view/9325/6177. Acesso em: 14 abr. 2019.

DESSEN, Maria Auxiliadora; SILVA, Nara Liana Pereira. Síndrome de Down: Etiologia, caracterização e Impacto na Família. Revista: Interação em Psicologia, Paraná, v. 6 n. 2 p. 167-178, 2002.

FREITAS, Camila Siqueira Cronemberger. Interação social entre pares: a importância do brincar para a inclusão escolar de crianças com Síndrome de Down, 2010. 157f. Dissertação (Mestrado em Educação) - Universidade Federal do Piauí. Teresina. Disponível em: http://ufpi.br/arquivos_download/arquivos/ppged/arquivos/files/dissertacao/2010/Camil a_Siqueira.pdf. Acesso em: 15 jan. 2019.

GABRILLI, Mara. Brinquedos e Brincadeiras inclusivos. Brasília; DF: Ministério da Cultura, 2018. em: http://institutomaragabrilli.org.br/images/stories/pdf/brinquedos.pdf. Acesso em: 07 abr. 2019.

GAIA, Ronan da Silva Parreira. Educação Especial no Brasil: Análises e reflexões. 2017. Disponível em: http://docplayer.com.br/53516413-Educacao-especial-no-brasilanalises-e-reflexoes.html. Acesso em: 15 jan. 2019.

GOLDENBERG, Mirian. A arte de pesquisar: Como fazer pesquisa qualitativa em Ciências, 8. ed. Rio de Janeiro: Record, 2004.

KRAUSE, Maggi; VICHESSI, Beatriz; SILVA, Wellington Soares. Caderno Brincar: Propostas práticas para brincadeiras inclusivas na Educação Infantil. v. 2. São Paulo: Associação Nova Escola, 2018. Disponível em: https://fundacaovolkswagen.org.br/wpcontent/uploads/2018/12/Apostila-Brincar-Volume-2.pdf. Acesso em: 15 abr. 2019.

LÜDKE, Menga; ANDRÉ, Marli E.D.A. Pesquisa em educação: abordagens qualitativas. São Paulo: EPU, 1986.

NONAKA, Katia Leiko; POTTKER Caroline Andrea. Percepção de professores sobre a Inclusão no ensino Regular de Alunos com Síndrome de Down, Revista Uningá- Curso de Psicologia da faculdade Ingá, v. 23, n. 3, p. 52-60, jul./set. 2015. Disponível em: http://revista.uninga.br/index.php/uningareviews/article/view/1653/1265. Acesso em: 15 abr. 2019.

SANTANA, Adriana Silva Andrade. Educação Inclusiva no Brasil: Trajetória e Impasses na Legislação. 2016. Disponível em: https://portal.fslf.edu.br/wpcontent/uploads/2016/12/tcc_8.pdf. Acesso em: 14 jan. 2019.

SABINO, Leticia Akemi de Araújo Sakamoto. O brincar em crianças com Síndrome de Down. 2011.35f, Monografia (Terapia Ocupacional: Uma Visão Dinâmica em 
Neurologia) - UNISALESIANO Centro Universitário Católico Salesiano Auxilium. Lins-SP.

UNICEF - Fundo das Nações Unidas para a Infância - Guia do Brincar Inclusivo. Projeto Incluir Brincando. 2012. Disponível em: http://files.unicef.org/brazil/pt/br_sesame_guia.pdf. Acesso em: 15 maio 2019.

\section{Endereço do(a) Autor(a):}

Rejane Helena Damas

Endereço eletrônico: rejanezaza@ hotmail.com

Neil Franco Pereira de Almeida

Endereço eletrônico: neilfranco010@hotmail.com 